\title{
Application of data analytics for research of digital administrative services in Bulgaria
}

\author{
Plamen Milev ${ }^{1 *}$ \\ ${ }^{1}$ University of National and World Economy - Sofia, Bulgaria
}

\begin{abstract}
The article examines issues on the topic of digital administrative services in Bulgaria. In this sense, the paper presents the opportunities for application of data analytics, which are suitable for research of this type of services. In this case, the article uses data from online media content on the researched topic. The main purpose of the article is to apply opportunities for data analytics and to present the relevant analysis on the topic of digital administrative services in Bulgaria. To achieve its goal, the article uses various scientific methods, including study, analysis, research, modeling and experimentation. The results support the main hypothesis of the study, namely defining the benefits of applying data analytics to research the media positioning of digital administrative services in Bulgaria. In conclusion, the paper points out the opportunities for improvement of the research in the subject area with the application of the respective data analysis.
\end{abstract}

\section{Introduction}

Digital administrative services are a modern necessity for every society. Bulgaria is also investing heavily in improving the level of digital administrative services that the public sector provides to citizens and businesses. As a result of these efforts, more and more digital administrative services are available. This undoubtedly improves the level of the overall electrification process in the public sector. Most digital administrative services are developed at the regional level. In this sense, it is important to keep in mind that the services offered may differ significantly depending on regional specificities. It is logical to assume that the leading regions, which are typically the regions with the largest population, also have a better developed system of digital administrative services. At the same time, the ability to analyze data from a variety of sources is at the heart of an essential part of contemporary research in any subject area. The field of digital administrative services is no exception. This subject area is also of interest for research in the context of the possibilities for application of data analytics. From the point of view that the Internet is a world-renowned media of a new generation, we can conclude that the study of the way digital administrative services is positioned in the Bulgarian Internet space is a study of the media positioning of digital administrative services in Bulgaria. This study is the purpose of the article.

\footnotetext{
*Corresponding author:pmilev@unwe.bg
} 


\section{Methodological approach}

The study of the media positioning of digital administrative services in Bulgaria requires the use of appropriate tools. The topic is very relevant and for this reason there is a lot of research in the subject area. Much of this research assesses the level of digital administrative services, which is based on a developed methodology. In many cases, the relevant methodology is based on data from studies of official sources of information [1]. Some authors make an assessment based on the features of the respective software solutions [2]. Some studies have developed their own methodological solutions for evaluating administrative services in the public sector [3]. In the present study, the focus is on the possibilities for application of data analytics for research of digital administrative services. To achieve these goals, the media positioning of the researched topics in the Bulgarian Internet space is analyzed. The main components of the methodological approach are presented at Fig. 1.

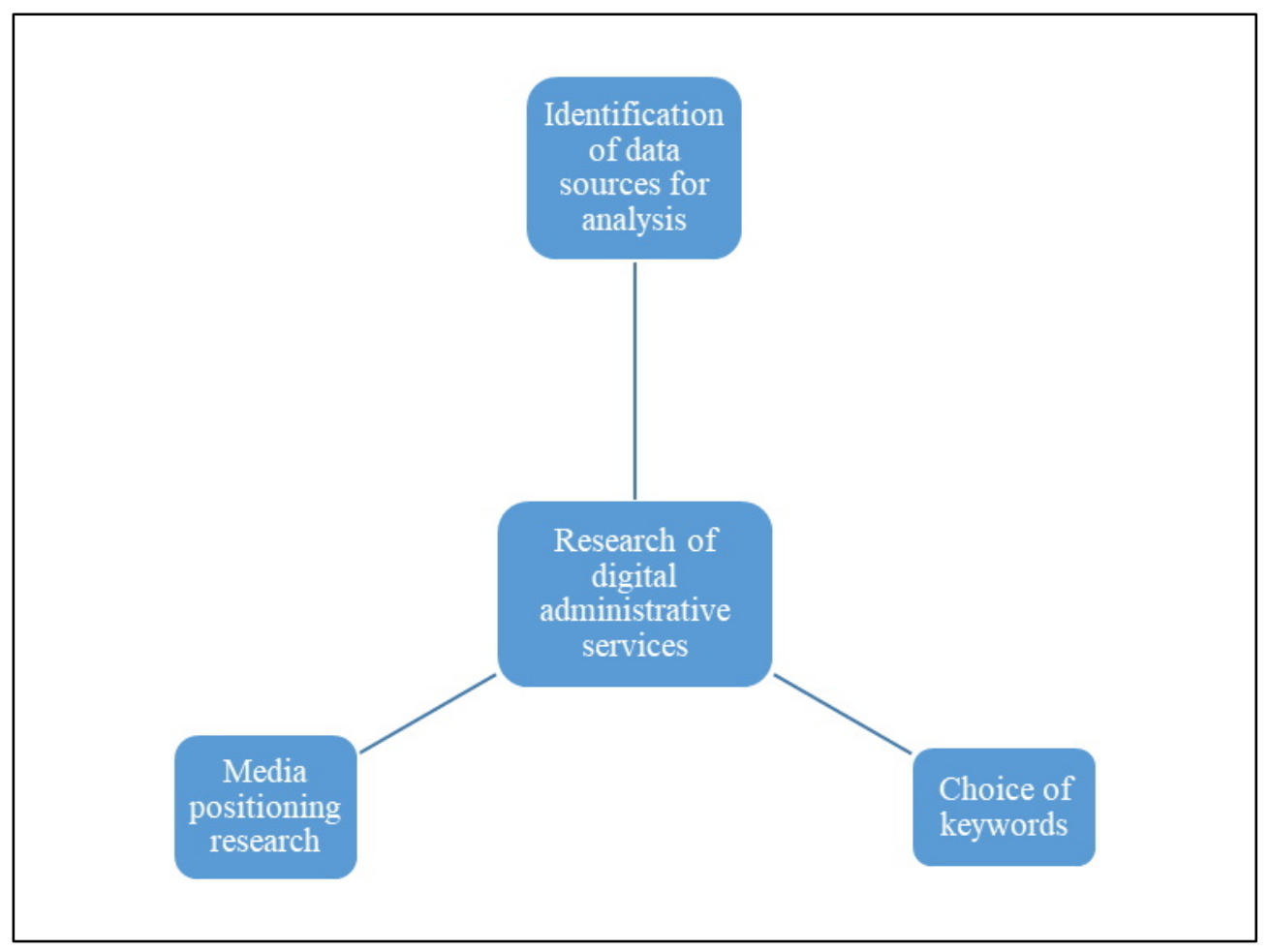

Fig. 1. Methodological approach for studying the media positioning of digital administrative services in Bulgaria

The proposed approach begins with identifying the data sources for the analysis. The regularities in the results that will be achieved largely depend on the data sources. In the analysis of social media, the positioning of digital administrative services will have one character, and in the analysis of print media - another. The next step in the approach is to choose keywords for the research. For this type of analysis, key words should be determined, with which the researched topic is associated in the media. The key words that digital administrative services are associated with in the media are most often the following:

- online services;

- digital services;

- Internet services;

- electronic services; 
- web services.

It is these keywords that are embedded in the methodological approach in the present study. The proposed approach ends with a study of the results for the respective media positioning of digital administrative services. This study depends on the data analysis method used. Depending on the method of analysis and the results obtained, the relevant conclusions can be drawn from the performed research. The proposed methodological approach is practically applied and in the next part of the research the obtained results are presented.

\section{Results}

The survey data are provided by a specialized information system for monitoring and analysis of online media content [4]. After applying the methodological approach presented in the study, several graphical analyses with application of data analytics are presented. Fig. 2 presents a quantitative distribution of the media positioning of the digital administrative services for the months of February and March 2020.

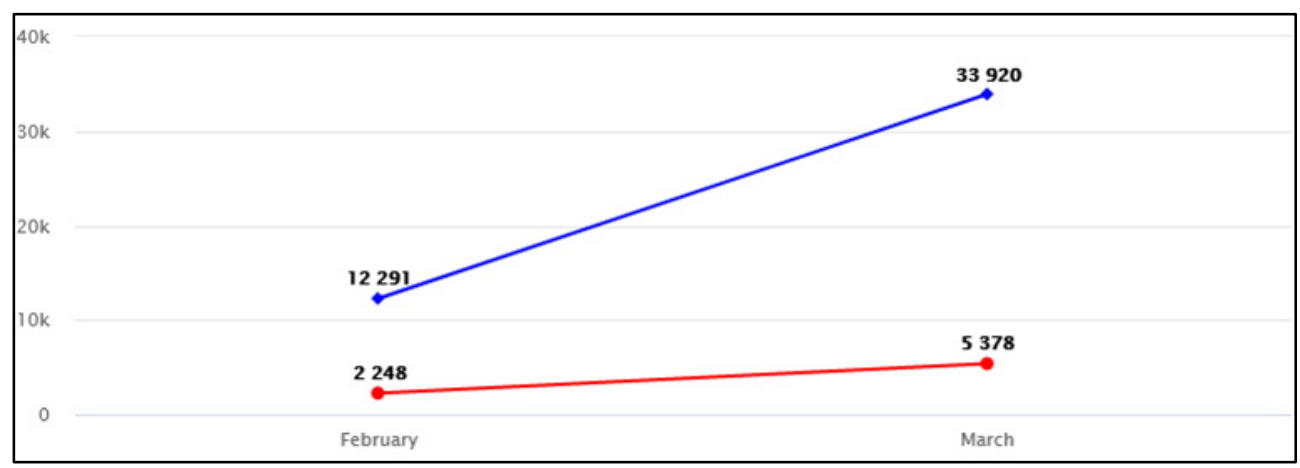

Fig. 2. Media positioning of digital administrative services in Bulgaria for the months of February and March 2020

The red line of the presented graph illustrates the increase of the publications for the period, and the blue line shows the change in the number of mentions (occurrences) of the keywords on the researched topic. The presented results show that from February 2020 to March 2020 the publications on the topic of digital administrative services have increased more than two times. Over the same period, keyword occurrences in the context of this topic have increased almost three times. These results clearly illustrate the increased interest in digital administrative services, which stands out in the studied media positioning. Another type of analysis that is of interest for the present study is the regional distribution of the media positioning of the researched topic. In regional terms, Bulgaria is divided into 28 districts [5]. The application of data analytics in this context evaluates the association of the keywords included in the study with these 28 regional units. Fig. 3 presents data on the regional distribution of media positioning of digital administrative services for a period of one year back in time (June 2020 - May 2021). 


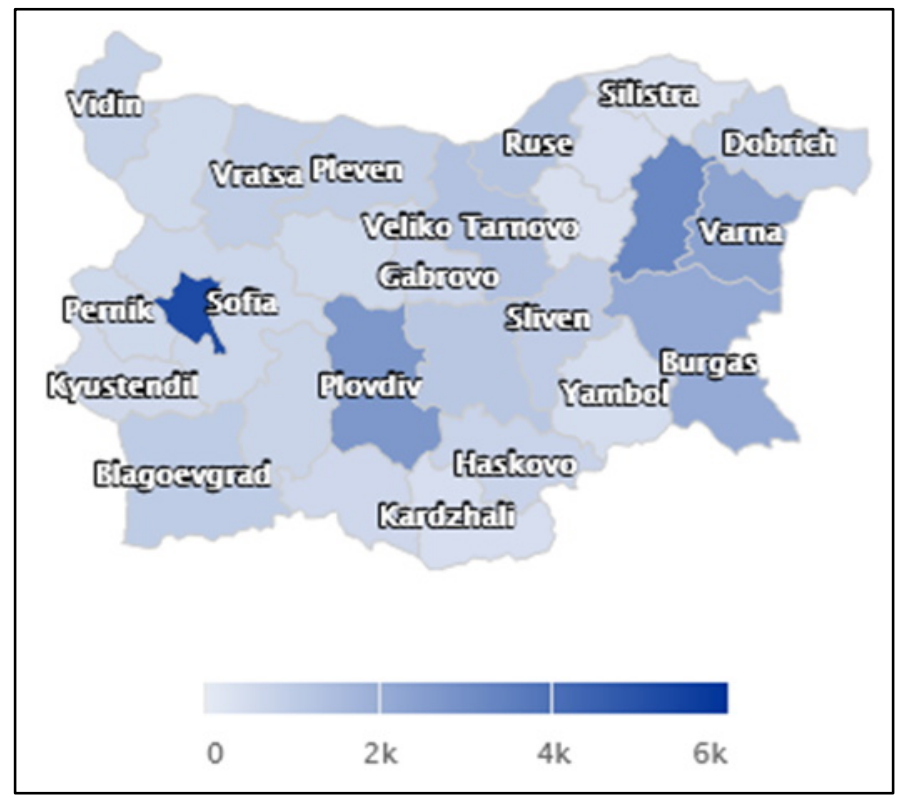

Fig. 3. Regional distribution of the media positioning of the digital administrative services in Bulgaria for the period June 2020 - May 2021

The graph clearly shows that the regions in Bulgaria with the most results from the applied approach are Sofia City, Plovdiv, Varna, Burgas and Shumen. The first four are the largest regions in Bulgaria and their presence in the top five is not a surprise. At the same time, Shumen's presence in this ranking deserves attention. The graphically presented data are described in detail in Table 1.

Table 1. Results from the graphic distribution - number of publications and number of occurrences in the online media

\begin{tabular}{|c|c|c|c|c|c|c|c|}
\hline & 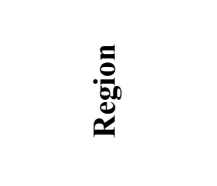 & 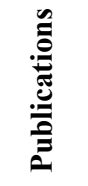 & 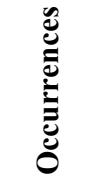 & & 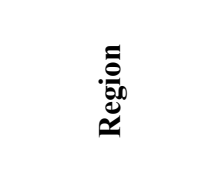 & 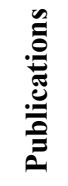 & 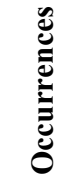 \\
\hline 1 & Sofia City & 5240 & 33508 & 15 & Haskovo & 768 & 4408 \\
\hline 2 & Shumen & 3241 & 29036 & 16 & Pazardzhik & 753 & 4800 \\
\hline 3 & Plovdiv & 2708 & 16094 & 17 & Gabrovo & 734 & 4570 \\
\hline 4 & Varna & 2322 & 14946 & 18 & Sofia (province) & 648 & 5941 \\
\hline 5 & Burgas & 2118 & 12538 & 19 & Smolyan & 636 & 4203 \\
\hline 6 & Veliko Tarnovo & 1333 & 7733 & 20 & Montana & 603 & 4584 \\
\hline 7 & Ruse & 1278 & 7874 & 21 & Pernik & 601 & 4040 \\
\hline 8 & Stara Zagora & 1180 & 7388 & 22 & Lovech & 587 & 3787 \\
\hline 9 & Blagoevgrad & 1027 & 6234 & 23 & Kyustendil & 580 & 3598 \\
\hline 10 & Sliven & 1001 & 6782 & 24 & Yambol & 457 & 3449 \\
\hline 11 & Vratsa & 960 & 5640 & 25 & Kardzhali & 416 & 2786 \\
\hline
\end{tabular}




\begin{tabular}{|l|c|c|c|c|c|c|c|}
\hline $\mathbf{1 2}$ & Pleven & 956 & 5074 & $\mathbf{2 6}$ & Razgrad & 410 & 2210 \\
\hline $\mathbf{1 3}$ & Dobrich & 887 & 6713 & $\mathbf{2 7}$ & Silistra & 399 & 2842 \\
\hline $\mathbf{1 4}$ & Vidin & 824 & 4048 & $\mathbf{2 8}$ & Targovishte & 375 & 2285 \\
\hline
\end{tabular}

As already noted, the Sofia City region has the most publications and occurrences of keywords according to the methodological approach. In it the number of publications is significantly higher than in other regions. This result seems extremely plausible given the much larger population of this region compared to other regions in Bulgaria [6]. Shumen follows, which is somewhat unexpected in advance. Then come the next largest regions in Bulgaria after the capital region - Plovdiv, Varna and Burgas. The regions of Veliko Tarnovo, Ruse, Stara Zagora, Blagoevgrad and Sliven have similar results. The first half also includes the regions of Vratsa, Pleven, Dobrich and Vidin. The differences in results between the regions below in the table are becoming smaller. At the bottom of the table are the regions of Yambol, Kardzhali, Razgrad, Silistra and Targovishte.

\section{Conclusion}

As a result of the study, the following conclusions can be drawn:

- there is a significant change in the media positioning of digital administrative services in Bulgaria, which increases significantly in March 2020;

- there is an increased consumer interest in the administrative digital services in Bulgaria, which is evident from the large number of media publications on the researched topic;

- the digital administrative services of the leading regions in Bulgaria - Sofia City, Plovdiv, Varna and Burgas are most often positioned in the media;

- together with the leading regions, the very serious media positioning of the digital administrative services in Shumen district is impressive;

- the least represented in the media according to the methodology applied in the study are the districts of Yambol, Kardzhali, Razgrad, Silistra and Targovishte.

The results of the research can serve as a basis for other research in the subject area, as well as to find practical application for analysis of the media positioning of digital administrative services in Bulgaria.

This work was supported by the UNWE Research Programme (Research Grant No. NID NI-7/2020).

\section{References}

1. National Statistical Institute (2021), https://www.nsi.bg/, [Accessed: 22 June 2021]

2. R. Kirilov, Econ. and Soc. Alternatives, 2, 127-140 (2017)

3. K. Kirilova, Econ. and Soc. Alternatives, 2, 43-57 (2018)

4. Media monitoring and analysis (2021), https://mediaboard.bg, [Accessed: 22 June 2021]

5. Regions in Bulgaria - Regional development (2021), https://www.mrrb.bg/en/regionaldevelopment/regions-in-bulgaria/, [Accessed 22 June 2021]

6. Population by districts, municipalities, place of residence and sex (2020), https://www.nsi.bg/bg/, [Accessed: 22 June 2021] 